\title{
PROYECCIONES EDUCATIVAS EN EL DISCURSO SOCIOPOLÍTICO DE PEDRO CHAPUIS (1826-1830*1
}

\section{EDUCATIONAL PROJECTIONS IN THE SOCIOPOLITICAL DISCOURSE OF PEDRO CHAPUIS (1826-1830)}

\author{
Rubén Núñez Vega² \\ rrnunez@uc.cl \\ Universidad de Los Lagos \\ Osorno, Chile
}

\section{RESUMEN}

En ninguna comunidad humana la educación surge de forma fortuita, sino que allí donde exista curiosidad, existirá el proceso de enseñanza-aprendizaje (Freire, 1970). La forma en que se ha desarrollado la educación en Chile, así como en la generalidad de las sociedades occidentales, guarda ciertas particularidades. En la educación formal chilena, la escolarización y la alfabetización de la población nacional tiene una finalidad evidente: la formación del Estado nacional (Serrano, Ponce de León y Rengifo, 2012). Esto quiere decir que las autoridades políticas e intelectuales comprenden la necesidad de generar un mecanismo estable y permanente para la difusión de ciertos principios morales, respaldados por un discurso civilizatorio. Por lo tanto, la pregunta que moviliza este estudio es el siguiente: ¿Cómo se construye la educación en Chile a inicios de la República, a través del impacto discursivo del militar napoleónico francés, Pedro Chapuis?

La investigación tiene por objetivo identificar los propósitos y el impacto discursivo de Pedro Chapuis sobre la educación en Chile, a través de la prensa, a inicios de la República.

Palabras claves: educación, Pedro Chapuis, discurso, prensa, Estad-nación.

\begin{abstract}
In no human community does education arise by chance, but where there is curiosity, there will be the teaching-learning process. The way in which education has developed in Chile, as well as in Western societies in general, has certain peculiarities. In Chilean formal education, the schooling and literacy of the national population has an obvious purpose: the formation of the national State. This means that the political and intellectual authorities understand the need to generate a stable and permanent mechanism for the diffusion of certain moral principles, backed by a civilizing discourse. Therefore, the question that mobilizes this study is the following: How is education built in Chile at the beginning of the Republic, through the discursive impact of the French Napoleonic military, Pedro Chapuis?

\footnotetext{
* Artículo recibido el 8 de enero de 2018; aceptado el 19 de marzo de 2018.

${ }^{1}$ Este artículo ha sido beneficiado con una beca otorgada por el académico e investigador Patrick Puigmal, responsable del proyecto Fondecyt $\mathrm{N}^{\circ} 1150263$.

${ }^{2}$ Licenciado en Historia de la Universidad de Concepción (2015), profesor en Educación Media de Historia de la Pontificia Universidad Católica de Chile (2016) y Magíster en Ciencias Humanas con Mención en Historia de la Universidad de Los Lagos.
} 
The research aims to identify the purposes and discursive impact of Pedro Chapuis on education in Chile, through the press, at the beginning of the Republic.

Key words: education, Pedro Chapuis, speech, press, Nation-state.

\section{Introducción}

La hipótesis consiste en que cierto grupo de europeos napoleónicos tienen una influencia intelectual en la construcción de conocimiento a inicios de la República en Chile, durante el siglo XIX. El caso de Pedro Chapuis, militar francés que cumplió un rol moralizador y civilizatorio, por medio de la difusión de sus ideales liberales y republicanos a través de la prensa nacional. Su influencia se identifica con un discurso marcado por el impulso de valores patrios, nacionales, de respeto a las leyes, y de formación de la ciudadanía, mediante la educación formal. De este modo, la intención es generar una proyección hacia el futuro, donde los debates en materia educativa se seguirán desarrollando y causando amplias controversias en la sociedad.

Respecto a la espacialidad y temporalidad de nuestra pesquisa, nos centraremos en la influencia que tuvo Pedro Chapuis en la fundación del Colegio de Santiago y el impacto discursivo que han tenido los postulados de este militar napoleónico en materia educativa, teniendo en consideración la escasez de estudios referentes a Pedro Chapuis. El siguiente artículo se divide en los siguientes apartados: rol de los militares napoleónicos en América Latina; el paso de Chapuis por Chile y sus visiones generales sobre la realidad local; y por último, el proyecto educativo de Chapuis y sus proyecciones.

\section{Militares napoleónicos en América Latina}

Para referirnos a Pedro Chapuis y otros militares napoleónicos que llegan a América Latina, recurriremos principalmente a Patrick Puigmal, quien realiza un seguimiento histórico a través de fuentes, para identificar y analizar el recorrido e influencia de estos personajes en el continente americano. A modo de contexto, Puigmal plantea que, al terminar la guerra en Europa, los militares optan por dos caminos. Por un lado, adscribir a un ejército en América Latina como continuación de la vida de armas, o, por otro, ejercer influencia desde la vida y visión de un civil ilustrado, involucrándose a través de discursos y la prensa en las decisiones políticas del nuevo territorio.

Para realizar una contextualización desde el marco internacional, 1808 es un año que marca la llegada de gran cantidad de personajes napoleónicos al continente americano, con la finalidad de consolidar el poder de José Bonaparte, en desmedro de España (Puigmal, "Brasil...", 2013, pp. 120). Márcia Reginal Berbel (2009, p. 36) se refiere a esta coyuntura política, explicitando la relación entre los militares y su influencia en América Latina: "Las invasiones napoleónicas en la Península lbérica politizaron de forma muy especial todas las elaboraciones relativas a la soberanía nacional esbozadas desde el siglo XIX."

Pedro Chapuis arriba a Brasil junto a una gran cantidad de franceses, "principalmente comerciantes oriundos de los puertos del Atlántico, [quienes] llegan entre 1814 y 1815, tras la caída del Imperio napoleónico" (Reginal, 2009, p. 123). Es interesante lo que plantea Puigmal 
respecto de la adolescencia de estos personajes europeos, pues la gran mayoría fueron educados bajo los principios de una política educativa imperial:

Todos estos franceses llegados a Brasil vivieron su adolescencia y la primera parte de su vida adulta bajo el régimen imperial y fueron formados en los liceos imperiales, primer intento de establecimiento de una política nacional de educación, política impregnada de los principios revolucionarios, como la libertad, la igualdad y la fraternidad, dentro de un marco republicano. (Reginal, 2009, p. 123).

Uno de los problemas que acarrean los ex militares napoleónicos en su llegada a América es el sinfín de prejuicios por su actividad previa, al migrar a un territorio en conflicto como lo es el latinoamericano. Por ello, "muchos militares se declaran comerciantes cuando desembarcan, pensando así evitar problemas con los poderes locales”. (Reginal, 2009, p. 124).

A partir de lo expuesto anteriormente, se evidencia el carácter trasatlántico de las ideas liberales e ilustradas, reflejadas en los militares napoleónicos que, tras su exilio, buscan nuevos parajes donde vivir y, además, consolidar su forma de interpretar la existencia como una teoría del deber ser de un ciudadano universal. Con ello, nace un nuevo paradigma para las élites chilenas: La educación formal como un paso para la construcción de un ciudadano civilizado, bajo los ideales europeos.

\section{Pedro Chapuis y su paso por Chile}

Sobre la vida de Pedro Chapuis, en sus estudios referentes a napoleónicos, europeos y liberales, Patrick Puigmal realiza una síntesis de los escasos datos que se pueden identificar sobre su vida personal. Recibe la influencia de Montesquieu en cuanto a la trascendencia de un sistema educativo en una República, aspecto que, para esta investigación, da sustento teórico al ideario político de Chapuis. Además, se manifiesta la conflictiva relación con los líderes de Brasil y, posteriormente, de Chile. Considerando que su periplo va de Francia a Portugal, España, Brasil, Chile y finalmente, Perú.

Es un personaje singular: oficial de caballería del ejército napoleónico, masón, profundamente liberal, se exilia después de 1815, combate y crea en España, justamente con Galli y Linati, una logia afiliada al Gran Oriente de Francia del cual José Bonaparte es el gran maestro. Luego va a Brasil donde crea un diario: El Verdadeiro Liberal, es expulsado por lo mismo (un diario brasileño lo describe en ese entonces como "anarquista expulsado de todos los países de Europa a causa de sus principios republicanos y llegado al Brasil solamente para fomentar la revolución"), y 
arriba a Chile en 1827 para crear El Colegio de Santiago, haciéndose así cargo de la máxima de Montesquieu 'es en el gobierno republicano que se necesita de toda la potencia de la educación. (Puigmal, “Napoleónicos...”, 2012, p. 128).

Vinculado a la filosofía de Jean Jacques Rousseau, en el discurso de Chapuis se evidencia que el ser humano renuncia a su libertad natural, ganando libertad civil y, por ende, su propiedad privada, lo que constituye un aspecto fundamental para la consecución del modelo político ilustrado. "Partió del concepto de que los hombres son todos, por derecho naturales, libres e iguales, para llegar a sostener que los gobiernos y los regímenes tienen su razón de ser y su fuerza solamente en la voluntad y en el consentimiento popular" (Altieri, 1970, p. 19). Con ello, cabe preguntarse ¿Cómo lograr el consentimiento popular? La respuesta está en el desarrollo de un aparato burocrático educativo que abarque todos los aspectos de la vida cotidiana.

En esa época, la prensa es un medio muy eficiente para perpetuar formas de pensar y proyectar la sociedad en que se está inserto, a pesar de la escasa alfabetización, los debates son constantes y perdurables en el tiempo. Antes de su llegada a Chile, en Brasil "algunos de sus artículos que insertó en aquel periódico [El Verdadeiro Liberal] hicieron que el emperador don Pedro encerrara primero a Chapuis en una prisión, i que en seguida le ordenara salir del imperio con absoluta prohibición de volver a pisar su territorio" (Velasco \& Orrego, 1872-73, p. 206). Antecedente que sirve para interpretar la complejidad de este personaje, al mismo tiempo intelectual y disruptivo frente a la autoridad.

Chapuis llega a Chile en 1827. Dentro del análisis de su personalidad a través del discurso, se interpreta como un personaje que genera grandes controversias en su redacción, al apoyar a bandos distintos en distintos periodos. Hay giros y variaciones en la filiación política de Chapuis en Chile. Al momento de arribar a Santiago, es un acérrimo opositor al federalismo. Sin embargo, en 1830, se une en su discurso a los liberales. Durante el conflicto entre pelucones y pipiolos, apoya a este último bando, junto con Benjamín Viel, José Rondizzoni y Eduardo Guticke. Por ello, tras la Batalla de Lircay, pierde todos sus cargos por haber sido partidario de los liberales (Puigmal \& Núñez, 2010). Es por estas contradicciones que Chapuis es interpretado por sus contemporáneos como un personaje que vende su pluma a intereses superiores.

A continuación, exponemos una fuente que plantea que los conservadores toman los servicios de Chapuis para combatir el federalismo. En cualquier caso, dejamos en claro que no se puede expresar en base a fuentes primarias o testimonios directos de Chapuis, que él haya sido parte de los servicios de los conservadores. Lo que se puede interpretar, a partir del periódico El Verdadero Liberal, es que en sus primeros años en Chile, Chapuis está en contra del sistema federal, por las libertades que se da a las provincias y la escasa autoridad que posee el Presidente:

Los conservadores le tomaron a su servicio, especialmente para que atacase a los federalistas, que hacían a la sazón extraordinarios esfuerzos para introducir en Chile 
la forma de gobierno, imitada de los Estados Unidos de Norte América (...). Chapuis creó con el propósito mencionado un periódico el cual llamó El Verdadero Liberal. (Velasco \& Orrego, p. 207).

Sus primeras publicaciones, que datan del año 1827, están relacionadas casi en exclusividad a las sesiones del Congreso Nacional. Allí, realiza reclamos en contra de las Asambleas Provinciales y ataca la incapacidad del Congreso para hacer frente a su administración, denuncia el ambiente de una posible guerra civil, y, por último, genera constantemente proyecciones para un gobierno centralizado, con un poder ejecutivo fuerte para dirigir los destinos de la nación. Este ideario político lo acerca a la figura de Diego Portales. Pero Chapuis era un defensor de Ramón Freire y, para cuando éste renuncia, el francés expresa su disconformidad con el Congreso, fustigando a personajes que considera incapacitados para conseguir la estabilidad necesaria en un contexto de vacío de poder.

Dentro de los aspectos teóricos que lo vinculan a la figura de Ramón Freire, se encuentra la adhesión a las leyes naturales, que según Chapuis, están por sobre las leyes escritas. Esto es parte de un discurso claramente ilustrado y universalista, en que se manifiesta el uso de la razón como principal puente para la estabilidad política:

Hallamos todas las garantías que podríamos desear: adhesión a la ley, no a la ley escrita, que no tenemos pero al menos a la ley natural: bajo su administración cada ciudadano estará siempre seguro de ser respetada su persona y propiedades; y si alguna vez una autoridad, viniese a pedirle permiso para aplicar una ley arbitraria, (...) respondería que como jefe de la justicia no podía hacerla servir para venganzas particulares. (...) En el momento en que el general Freyre se resuelva a gobernar, todo irá bien. (Chapuis, El Verdadero Liberal, 1827, №30, p. 3).

Este ideal universalista repercute en sus constantes críticas a las autoridades chilenas, pues considera en alta estima "La moral: mientras existan partidos en la nación, será con detrimento de la moral; pues ellos son movidos por las pasiones, y las pasiones engendran los crímenes" (Chapuis, El Verdadero Liberal, 1829, $N^{\circ} 65$, p. 2).

Tras la abdicación de Freire, el liberal Francisco Antonio Pinto asume la presidencia de la República. Chapuis también apoya a este militar, principalmente en su idea de disolver el Congreso y dar mayor poder administrativo al ejecutivo, bajo un carácter central y con facultades para la elaboración de leyes. Este aspecto es relevante de destacar, debido a que el establecimiento de las leyes, así como de una Constitución, es la manera de perpetuar en el papel los ideales ilustrados, a los que se apela durante el siglo XIX y principios del XX como proyección de la homogeneización social. Además, Chapuis hace un llamado a considerar el 
talento como factor preponderante para la obtención de cargos políticos, en una especie de meritocracia decimonónica, que en la práctica se reduce a un porcentaje mínimo de la población, dada la escasa alfabetización:

El Presidente Pinto en su carrera política debe haber estudiado demasiado el espíritu de la nación que va a gobernar; (...) que los empleos deben ser dados sólo al talento y a la probidad, que el Estado que no tiene leyes, no puede pasarse sin ellas por más tiempo. (Chapuis, El Verdadero Liberal, 1827, №37, p. 1).

Al cumplirse diez años de la Batalla de Chacabuco, Chapuis realiza una reflexión y balance, donde incita a la búsqueda de la felicidad a través de un buen gobierno, bajo los principios de la libertad individual. Frente a las críticas que recibe, en su defensa detalla el propósito de sus escritos: "Cuando di principio a este periódico no era mi intención entrar en semejante polémica. Los enemigos de la nación me han obligado a desviarme por algún tiempo del objeto que me había propuesto" (Chapuis, El Verdadero Liberal, 1827, № 10, p. 2).

El concepto de libertad está presente en todo el discurso de El Verdadero Liberal. Pero, ¿Qué entiende Pedro Chapuis por libertad? “(...) no seremos verdaderamente libres sino cuando sepamos positivamente lo que la ley nos permite y lo que nos prohíbe. Necesitamos un código nacional" (Chapuis, El Verdadero Liberal, 1827, № 12, p. 3). Este aspecto imperante para la elaboración de leyes está directamente relacionado a la supuesta libertad a que apela Chapuis.

Un ejemplo de su discurso unitario, y contrario al Congreso, ya que según él "todo lo rechaza" (Chapuis, El Verdadero Liberal, 1827, $\mathrm{N}^{\circ} 2$, p. 4). se encuentra en el texto fechado el 2 de marzo de 1827, donde realiza una crítica a la estructura de 8 provincias, dada la complejidad administrativa y regulatoria que conlleva. Chapuis considera, además, que es más complejo gobernar dando cierta autonomía a las provincias, debido a que no existe una Constitución que establezca los parámetros de acción de cada provincia (Chapuis, El Verdadero Liberal, 1827, № 14, p. 1). Por lo tanto, su opción es mover la maquina desde el centro. A partir de esto, se puede inferir que el futuro establecimiento de un Colegio en Santiago, era uno de los primeros pasos burocráticos para fomentar este centralismo, basado en la moralidad y la regulación del comportamiento de la población:

Componiéndose el Estado de ocho provincias, y no guardando proporción ninguna su población y recursos, (...) el Estado está en su infancia, no puede cargársele con trabas que impidan su adelantamiento, (...) Me he decidido por el sistema unitario, porque estoy convencido que los pueblos gozarán más libertad bajo éste; tanto en la administración general como en la particular (...). Quiero la unidad porque todos los 
resortes que hacen mover la máquina, se reúnen en un centro, y le dan más fuerza a su acción. (Chapuis, El Verdadero Liberal, 1827, № 15, p. 1).

Para sintetizar el pensamiento de Chapuis desde sus principios ilustrados y liberales, señala que los individuos libres pactan la construcción de la sociedad civil con el Estado, para que éste garantice libertades y derechos (Aljovín \& Araya, 2005, pp. 118-119). Por ello hace hincapié en la existencia de un poder centralizado, para resguardar estas libertades que permiten el pacto social. Las características críticas de su personalidad son interpretadas por el investigador Michael Oakeshott como parte de la matriz racionalista en la política. Lo define como un personaje que "es a la vez escéptico y optimista: escéptico porque no existe opinión ni hábito ni creencia ni nada tan firmemente arraigado o sostenido en forma tan generalizada como para que no quepa cuestionarlos o juzgarlos según lo que él llama su 'razón'; optimista porque nunca duda de la eficacia de su 'razón' (cuando es aplicada correctamente) para determinar el valor de una cosa, la verdad de una opinión o la propiedad de una acción" (Oakeshott, 1947).

Se puede afirmar que, más allá de su proyecto educativo, Pedro Chapuis fue un personaje controversial, toda vez que daba argumentos en cada una de las materias que involucraban la construcción del Estado nación. Su motivación principal es la disolución del Congreso, debido a que juzga escasa su organización, mala su regulación de los fondos económicos, y poco el control que sobre él ejercía el Ejecutivo. Critica, además, el egoísmo de los legisladores, de quienes piensa que no construyen políticas con proyección, sino que son sus pasiones individuales las que determinan sus acciones.

Como vemos, este francés ilustrado y militar de caballería no está exento de críticas, principalmente debido a que es un liberal con tendencia al centralismo, lo cual produce un gran revuelo en la época. Sin embargo, esto puede ser entendido por su inclinación favorable al libre comercio, su creencia en leyes naturales a través de la libertad individual y la propiedad privada y, a su vez, la promoción de un gobierno fuerte que supere la inestabilidad política que se vive en el territorio.

\section{Pedro Chapuis y su proyecto educativo}

Para tratar el proyecto educativo y formador de Estado propuesto por Pedro Chapuis, debemos comprender la relevancia y trascendencia que tiene la filosofía francesa, específicamente del movimiento ilustrado. Dicho aspecto envuelve completamente a nuestro personaje central, así como al grueso de militares europeos devenidos en influyentes civiles en América Latina. Como señala Puigmal, "más que simples comerciantes, los libreros franceses se han transformado entonces en los agentes de la ilustración, haciendo entrar al país en la era del constitucionalismo: sus productos (los libros) se transformaban en ideas y su filosofía en ideología" (Puigmal, "Brasil...", 2013, p. 140). El hecho de ser militares napoleónicos no los limita a desempeñarse en otras áreas, ya sean comerciales, intelectuales y también castrenses. En el caso de Chapuis, va a expresar su proyecto intelectual en las publicaciones de El Verdadero Liberal. 
Sobre los aspectos centrales del discurso de Chapuis, existe una búsqueda constante de un sistema político que sea representativo de la llustración como movimiento de aspiraciones universales. Es decir, un sistema que busque la construcción de un ciudadano global, bajo los parámetros del progreso indefinido. En este sentido, Chapuis comprende la educación como "uno de los ejes de formación de la ciudadanía y, por lo tanto, como un factor de estabilidad del nuevo gobierno" (Puigmal, Napoleónicos..., 2012, p. 27). Dicha estabilidad hay que entenderla como una estrategia para la obtención de lealtad por parte de los nuevos ciudadanos, con el fin de preservar lo que se está construyendo como Estado-nación. La doctrina liberal genera en la ciudadanía un imaginario en el que expone un ideal de sujetos libres e iguales en derechos y que comparten decisiones colectivas, pero que sin embargo termina siendo el privilegio de una pequeña parte de la población (Aljovín \& Araya, 2005, p. 102).

Chapuis defiende que lo que se espera de un gobierno es el patriotismo y la energía que involucra este concepto. "Estos mismos hombres deben además mantenerse firmes en los principios que han adoptado para gobernar; ellos deben ser su única guía" (Chapuis, El Verdadero Liberal, 1827, $\mathrm{N}^{\circ} 2$, p. 3). Al ser un personaje que promueve la llustración, Chapuis plantea recurrentemente ejemplos de Francia, que es la cuna de esta ideología. Reconoce el fracaso de imponer estos ideales en Europa, recalcando la compleja misión que conlleva intentarlo en Estados nacionales que están en etapas primarias (Chapuis, El Verdadero Liberal, $1827, N^{\circ} 2$, p. 2). De esto se infiere que su proyección educativa en Chile responde a esta misma complejidad.

Uno de los eventos que marca la primera estadía de Chapuis en Chile es su detención en un cuestionado contexto donde no hay libertad de imprenta. Estas quejas provenían especialmente del bando federalista, y dentro de sus argumentos se encuentra el lenguaje despectivo y la falta de moderación al momento de tratar los temas vinculados al sistema de gobierno a implementar. Consideramos este aspecto dentro de las proyecciones educativas del francés, puesto que la libertad de imprenta es un mecanismo eficiente -hasta la actualidad- para controlar el conocimiento que circula. Esto es independiente de la difusión que pueda tener en el momento, pues, como hemos señalado, es bajo el alcance de los periódicos, por la escasa alfabetización del pueblo.

En 1827, Pedro Chapuis es detenido por infracción a la Ley de Imprenta (Villagra, 2017, p. 231). Él realiza una crítica, sentenciando que "no sólo se anula la libertad de la prensa, sino que limita hasta la de pensar" (Chapuis, El Verdadero Liberal, 1827, $\mathrm{N}^{\circ}$ 27, p. 2-3). La Aurora, consecuente con la valoración de la libertad de imprenta, se refiere a la detención de Chapuis:

El objeto de este artículo no es defender a Mr. Chapuis: se reduce a sostener la libertad de la imprenta, atacada en un escritor público, para el cual se han atropellado 
los trámites, que seguramente le hubiera conducido hasta el caso de oír un fallo que

le condenase con seguridad. (El Alcornoque, $N^{\circ} 10,8$ agosto 1827, p. 1). ${ }^{3}$

Dentro de sus proyecciones a nivel estatal, que según nuestra interpretación involucran el aparato burocrático de la educación, Chapuis plantea la idea de un gobierno que se adapte y comprenda la realidad de su contexto. Se trata de un aspecto revolucionario para la época, a partir del cual cabe preguntarse si el modelo ilustrado debe replicarse en América tal como se construyó en Europa o si acaso debe adaptarse a la realidad local. En el análisis de este caso, entendemos que la forma de aplicar el modelo ilustrado es transformando la mentalidad de la población. Es decir, se trata de un proyecto a largo plazo, que descansa en la imposición de un modelo educativo, impulsado por privados franceses, apoyados económicamente por el Estado chileno, y que apunta directamente a modificar las costumbres de los habitantes del territorio:

Desengañémonos: no gobernarán a Chile las utopías sino un buen sistema apropiado a un conocimiento exacto de las costumbres de los habitantes, y a un justo discernimiento de las necesidades reales y de las ficticias. Chile necesita de un gobierno verdaderamente constitucional y de un hombre de genio que le dirija. (Chapuis, El Verdadero Liberal, 1827, №5, p. 2).

En la misma línea de buscar una manera de adecuar contextualmente la llustración en Chile, Chapuis postula que, para la elaboración de una Constitución, "no ha de ser precisamente ni la de Estados Unidos, ni la de Méjico, ni la de otro Estado cualquiera. Se necesita una que sea especial, en que estén consagrados clara e irrevocablemente los principios fundamentales" (Chapuis, El Verdadero Liberal, 1827, № 5, p. 2).

Dentro del discurso de Chapuis se encuentra el aspecto moral, el desarrollo industrial y la extracción de recursos naturales. Estos dos últimos, son intereses transversales para gran parte de los intelectuales de la primera mitad del siglo XIX. La siguiente cita apunta directamente a los comerciantes y campesinado que, en su mentalidad y forma de vida, no se interesa por la explotación excesiva de los recursos: "Lo que arruina a Chile es la dependencia del extranjero en que se encuentra, y esta dependencia cesará cuando Chile sea verdaderamente nacional" (Chapuis, El Verdadero Liberal, 1827, № 40, p. 2).

Por la interpretación anterior, se hace urgente poseer un modelo educativo que potencie en los ciudadanos una conciencia sobre el entorno, como un espacio para la extracción económica. Acerca del fomento industrial, Chapuis defiende la relevancia de la instrucción e ilustración, para

\footnotetext{
${ }^{3}$ La crítica a Chapuis no escapaba de nada. Por ejemplo, por haber comentado en su periódico que lo jóvenes chilenos están ejercitándose en gimnasia, anticipando que "algún día harán piruetas como en Paris", fue considerado un agravio en contra de costumbres y forma de ser del chileno, que tiene "modales decorosas" y no "frivolidades" catalogadas incluso de "ridículas". (1827, 8 agosto, n¹0, p. 2.). Villagra, 2017 , p. 232-233.
} 
formar nuevas fábricas, en las que se ponga en práctica el desarrollo tecnológico y cese así la dependencia con las potencias europeas. Su propuesta es prohibir la venta de las materias primas al extranjero, para que Chile desarrolle una industria propia en la cual produzca mercancías a partir de las materias primas existentes en el territorio nacional. Pero enfatiza en que sean los privados quienes realicen las primeras inversiones, y sean los europeos de quienes aprendan las ciencias y técnicas industriales. (Chapuis, El Verdadero Liberal, 1827, № 48, p. 3).

En febrero de 1827, Pedro Chapuis se pregunta qué hace falta para ser felices, a lo que responde: "Muy poco: buenas leyes, y hombres capaces de hacerlas ejecutar" (Chapuis, El Verdadero Liberal, 1827, № 10, p. 3). La educación, por lo tanto, ¿sería un medio para alcanzar este objetivo de felicidad? Lo más probable es que, según el ideario político de Chapuis, la respuesta sea sí.

El proyecto educativo de Pedro Chapuis comienza en 1827, con la redacción de su periódico. Pero deja Chile a fines de ese año, para irse a Francia y retornar a fines de 1828. Debido a la contradicción en las fuentes, se desconoce tanto el motivo como el financiamiento que recibió el francés para emprender estos viajes (Vidal, Discurso, 1874). Este hecho es documentado, principalmente, por la venida de Claudio Gay a Chile, quien cumple un rol preponderante en el desarrollo intelectual y científico de nuestro país.

Así llegamos a la creación del Colegio de Santiago. "Chapuis había organizado en París una sociedad de profesores para abrir en Chile bajo su dirección una casa de educación" (Velasco \& Orrego, 1872-73, p. 207). Es más, "según El Mercurio de Valparaíso, número 31, tomo II, fecha 10 de diciembre de 1828, el belicoso periodista traía dos proyectos muy heterogéneos, pero los dos muy pacíficos, a saber: el establecimiento de una fábrica de cristales, i la fundación de un colegio" (Velasco \& Orrego, 1872-73, p. 207). Respecto del primer proyecto, no se ha encontrado mayor evidencia, pero sobre la creación de un establecimiento educativo promovido por intelectuales franceses, las fuentes son categóricas al darle protagonismo a la gestión de Chapuis.

Raúl Silva entrega el listado de los docentes que acompañan a Chapuis en el viaje de Francia a Chile. Para ello,

es preciso retroceder hasta el día 11 de abril de 1828, pues entonces se firmaba, ante el notario parisiense M. Dominique Lambert, un contrato de asociación entre don Pedro Chapuis y un grupo de profesores que con éste saldrían rumbo a Chile. Los profesores aludidos, Francisco Alejo Río, Juan Antonio Portes, Claudio Gay, José Coupelon, Luis Teodoro Moriniere, Augusto Diosdado Verdollín, Francisco Lubin Gillet de Laumont, se unieron con la sana intención de crear en Chile 'un colegio con 
el título de Universidad' (...). Desembarcaron en Valparaíso, en cumplimiento del contrato, el 8 de diciembre de 1828. (Silva, 1965, p. 37).

En escritos del mismo Chapuis, afirma: "En cuanto a mi salida de Francia, no puede ser sospechosa. Fue autorizada sobre un buque del Estado, por un favor especial del vice-almirante Duperrey" (Chapuis, El Verdadero Liberal, 1829, № 79, p. 2). Por lo tanto, su viaje habría sido respaldado desde Francia.

Después de veinte meses de ausencia en Chile, Chapuis vuelve a la carga con preguntas dirigidas justamente a la atención sobre los asuntos morales:

[¿]La justicia civil y criminal han sido el objeto de los cuidados de los legisladores? ¿La enseñanza pública ha progresado? ¿La policía ha sido dirigida bajo unas bases más extensas y más filantrópicas? ¿Ha echado raíz el crédito público? ¿Se han procurado arbitrios para desenvolver el origen de aquella moral humana que señala las obligaciones del hombre? ¿Y aquella moral divina que señala nuestros deberes para con Dios sin el auxilio de la hipocresía y del fanatismo? (Chapuis, El Verdadero Liberal, 1829, $N^{\circ} 65$, p. 1).

Y sus respuestas se encaminan a la necesidad de afirmar su propio proyecto educativo, caracterizado por la invitación de los intelectuales franceses:

La instrucción pública si no ha hecho hasta el presente grandes progresos, es de esperarlos en lo porvenir; por todas partes se establecen colegios, y el Instituto Nacional que aparece en primer lugar, promete con su nueva administración, dar al estado ciudadanos virtuosos e instruidos. (Chapuis, El Verdadero Liberal, 1829, № 65, p. 1)

Ya en Chile, retorna a la polémica, esta vez junto a su grupo de compatriotas, quienes, según la Gaceta de Chile, "no parecen tener una conducta llena de nobleza" (Velasco \& Orrego, 1872-73, citando a la Gaceta de Chile, p. 332). A causa de la gran cantidad de detractores con que contaba, esta supuesta falta de nobleza de sus convidados va a jugarle en contra a Chapuis, sumado a que se le agotan los recursos para su proyecto. Es por ello que recurre a la facción conservadora para recibir apoyo económico y concretar así su empresa educativa. Esto indica un posible contrato previo entre el francés y los conservadores, o el simple auxilio monetario a un grupo que resultaba afín por la oposición de Chapuis al federalismo: 
Había costeado el viaje hasta Valparaíso de los profesores franceses, pero llegado allí, se encontró agotado de recursos pecuniarios. Parece que la generosidad del rey cristianísimo, tan decantada por Chapuis, había tenido límites harto estrechos. Viéndose en tales apuros, Chapuis imploró el auxilio de sus amigos políticos los conservadores, aquellos a quienes había servido en las columnas del Verdadero Liberal. (Velasco \& Orrego, 1872-73, pp. 208-209).

Sobre el financiamiento para su viaje a París, no existen evidencias concretas. Se sabe, sin embargo, que la travesía fue en una nave de transporte de la marina real francesa, que venía al Pacífico. "Esta circunstancia fue más tarde explotada por aquel aventurero como una prueba de que el rey Carlos X protegía su empresa" (Revista Chilena, 1875-76). Si ésta fue la forma como consiguió la ayuda económica, resulta interesante de destacar las proyecciones sociopolíticas proyectadas por el rey Carlos $\mathrm{X}$ en América Latina, al apoyar una empresa con la finalidad de crear un sistema educativo.

Los materiales pedagógicos para la promoción del colegio que proyectaba fundar eran "una biblioteca de más de dos mil volúmenes, una colección abundante i escogida de instrumentos de física i de química, otra de muestras de dibujo, i gran número de plantas i semillas desconocidas en el país" (Velasco \& Orrego, 1872-73, p. 208). Esto refleja su profesión de médico y científico en áreas vinculadas a la naturaleza, mismo interés que presenta Claudio Gay. Además, en caso de transportar más de dos mil libros, quiere decir que el propósito no tan sólo es instruir a la población, sino que construir conocimiento a través del estudio teórico y de campo. En otras palabras, buscaba abarcar el mayor grado de aspectos relacionados a la mentalidad de los habitantes del territorio nacional, con la finalidad de generar una transformación de sus patrones conductuales y mentales.

José Joaquín de Mora, escribe sobre Chapuis en El Mercurio de Valparaíso, denunciando su retorno y desconfiando de estas nuevas formas de enseñanza. En consecuencia, el supuesto acto de buena fe para potenciar la educación en Chile, es visto como una artimaña para monopolizar el conocimiento, en base a los postulados de extranjeros europeos:

La llegada del nunca bastante ponderado truchimán i caballero de industria M. de Chapuis en calidad de director e introductor de una corporación de hombres científicos en Chile, ha sido mirada con poca atención por los amantes de la libertad $\mathrm{i}$ del orden que duermen bajo sus laureles; no así por los famosos monopolistas llamados estanqueros, quienes no pierden ocasión para contrariar la marcha del gobierno i de la constitución aborrecida por ellos, porque no es fabricada en sus 
talleres. (...) Dicen que Carlos X, patrono de los hijos de Loyola, costea el viaje a Chapuis con toda su gente, un buque de guerra los conduce por cuenta de la persona del rey, quien de su bolsillo privado hace este presente a los hijos de Arauco; les suministra libros de su biblioteca, instrumentos de física, de química, plantas, semillas, etc. Le diremos: ¿Por qué, señor Carlos, tan obsequioso con los demócratas? (...) A estos señores sabios profesores, que vienen colegiados i convenidos por contrata a vivir en comunidad, que nos quieren educar a su modo, les contestaremos: Timeos Danaos. ${ }^{4}$

Utilizando la misma metáfora, Mora continúa su discurso y nos entrega otro dato. Según él, Chapuis era financiado por los estanqueros para la redacción de su periódico:

¡Alerta americanos, no nos durmamos, ni nos dejemos alucinar. Un regalo de Carlos X, presentado por Chapuis, recibido a brazos abiertos por los estanqueros monopolistas i apoyado por los fanáticos i beatos, no es moneda corriente (...). Nos destruirán; i entonces lloraremos pérdida de nuestros más caros intereses, i no podremos decir: Timeo danaos et dona ferentes. (Velasco \& Orrego, citando a El Mercurio de Valparaíso, 1872-1873, pp. 210-211).

Las disputas intelectuales entre Mora y Chapuis pasaron a formar parte de la práctica cotidiana en el conflicto entre liberales y conservadores. No obstante, todo se tornó más complejo para el francés cuando los conservadores le dan el protagonismo a Juan Francisco Meneses para dirigir el Colegio que se tenía, en aquel entonces, proyectado fundar:

Desde los primeros días de su arribo a Chile, los profesionales contratados por Chapuis se vieron envueltos en dificultades de todo género. (...) El intrigante Chapuis vivía en continuas riñas con sus compañeros. Todo hacía presentir la disolución de aquel proyectado colegio, cuando los corifeos del partido conservador lo tomaron bajo su patrocinio, separaron de su dirección a Chapuis para confiarla al presbítero don Juan Francisco Meneses, i lo inauguraron resueltamente con el nombre de

\footnotetext{
${ }^{4}$ Se hace referencia a la frase: Timeo danaos et dona ferentes, que quiere decir: Desconfío de los griegos, aunque traigan regalos.
} 
Colegio de Santiago. Este establecimiento tuvo por segundo director a don Andrés Bello. (Revista Chilena, 1875-76, p. 275).

Para respaldar la interpretación anterior que aparece en una de las biografías de Claudio Gay, existe una carta enviada de Diego Portales a Pedro Chapuis, en la que tratan el tema del Colegio de Santiago. Con fecha 2 de febrero de 1829, Portales parece dar su apoyo a Chapuis, en relación con los problemas existentes entre el redactor del periódico y los profesores franceses y le plantea que "lo que conviene es hacer el último esfuerzo para abrir la casa y establecerla."

Todo se complejiza hacia junio de 1829, cuando Pedro Chapuis interpone una demanda contra los profesores e intelectuales franceses que él mismo invitara:

puso demanda contra los profesores del Colegio de Santiago, sobre cumplimiento de una contrata relativa al caso. Los profesores, sin contestar derechamente, oponen la excepción de declinatoria, expresando que habiendo sido celebrada la contrata entre franceses, y en París, no reconocer autoridad en Chile para juzgar cosa alguna con relación a ella. (Chapuis, El Verdadero Liberal, 1829, №73, p. 4).

Para dilucidar el fallido proyecto educativo de Pedro Chapuis, la fuente de mayor utilidad son las cartas que escribe Diego Portales, explicando la situación al momento de enfrentarse al francés. El apoyo que le diera el 2 de febrero se ve truncado. En una misiva que insertó en el Crisol de Valparaíso, número 1, tomo I, 19 de julio de 1829, Portales explica que Chapuis le pide dinero, dado que los profesores franceses estaban siendo seducidos por Mora para ser parte del Liceo de Chile, y que este dinero sería destinado a financiar los gastos del viaje de Valparaíso a Santiago." (Velasco \& Orrego, citando al Crisol de Valparaíso, 1872-73, p. 226).

Continúa Portales, en referencia a que los profesores franceses le plantean la poca capacidad de organización de Chapuis, desmintiendo lo que éste había planteado en un comienzo:

El señor Chapuis me propuso una entrevista con ellos i la acepté de buena voluntad (...) Concluyeron [los profesores] con decir que ellos tenían su único origen en la falta de espera i mala inteligencia del señor Chapuis, i que jamás habían pensado en faltar a sus deberes. Confieso que la conducta que observé en los profesores me hizo dudar de la verdad de cuanto se les había imputado; i tomando la palabra, les hablé de esta manera (...). (Velasco \& Orrego, citando al Crisol de Valparaíso, 1872-73, p. 227). 
Portales agradece y reconoce la llegada de los intelectuales franceses a Chile, pero al parecer es uno de los políticos que influye en la decisión de restarle créditos a Chapuis, en virtud de buscar a otro personaje que se encargue de la misión de crear un colegio de corte conservador:

Ustedes se aprovecharán de esta clase de educandos, que a mi entender es la más numerosa [hablando del pupilaje]. El proyecto benéfico que movió a Ustedes a dejar su patria va a ser protegido por personas de concepto, de relaciones i propiedades, i con tal apoyo no debe temerse del éxito mientras que la conducta de Ustedes no desmerezca su confianza. Mocha circunspección-unión [sic] i el más alto desprecio de los frívolos ataques que han comenzado a dirigirse contra Ustedes, es lo que más conviene. (Velasco \& Orrego, citando al Crisol de Valparíso, 1872-1873, p. 227).

En cuanto a la relación de Chapuis con los profesores franceses invitados por él, sólo se tiene como fuente primaria lo que escribe Diego Portales en la carta que hemos estado reproduciendo. A continuación, Portales expresa la inoperancia de Chapuis para hacer frente a los inconvenientes que le aquejan, al punto de caer en los golpes para dar solución a la confección del Colegio:

Se fue el señor Chapuis con ellos a Santiago, i no cesó escribirme quejándose de su comportación [sic], i asegurándome que el señor Mora seguía empeñado en cruzar su plan minando a los profesores, i que era de esperar que los esfuerzos de aquel no quedasen sin fruto. En la carta que dio lugar a la contestación inserta en el número 76 del Verdadero Liberal, me dice que había llegado a tal grado la mala conducta de la canalla francesa que se había visto en la precisión de dar a uno de ellos de chicotazos en la cara; i me pide le aconseje lo que debía hacer para superar los inconvenientes i contradicciones que se oponían a cada paso a la realización del proyecto. (...) Dio la casualidad que en el mismo día, recibí dos cartas de Santiago en que se me afirmaba que uno de los profesores había demandado a Chapuis ante el cónsul francés por haberle hurtado unos cajones de cigarros; i que otro (don Juan Antonio Portes) lo había maltratado con fuertes golpes en la calle pública. (...). (Velasco \& Orrego, citando al Crisol de Valparaíso, 1872-73, p. 228). 
Debido a este conflicto, se puede inferir por qué Meneses queda a cargo del Colegio de Santiago. Además, la fecha de este conflicto, comienzos del año 1829, coincide con el cambio de discurso que presenta Chapuis en su periódico. Justamente, pasa a formar parte del bando liberal, desde donde apoya a quien fuera su más acérrimo contrincante, el mencionado José Joaquín de Mora.

Meneses i casi todos los profesores franceses se habían asociado, e iban a abrir en pocos días cerca de la plaza principal un establecimiento que se denominaría Colegio de Santiago. (...) Como era un individuo muy arrebatado, buscó al punto a los liberales; i del día a la noche se puso a su servicio. Chapuis continuó la publicación del Verdadero Liberal, el 30 de abril de 1829. (Velasco \& Orrego, pp. 331-332).

Es así como fracasa el proyecto del francés e intelectual Pedro Chapuis. A pesar de este naufragio, la disputa reflejada anteriormente es ejemplo y antecedente para la configuración de décadas tumultuosas, sin objetivos claros ni proyecciones que tengan algún sentido venidero en la cotidianeidad de Santiago, primeramente, y de Chile en general. Chapuis queda como un personaje olvidado en gran parte de la historiografía, aunque su importancia estriba en la búsqueda de intelectuales para la configuración de un sistema educativo, entre quienes destaca Claudio Gay, con la finalidad de instruir a la población chilena, de construir conocimiento y monopolizarlo a través de la imposición de una nueva moral y una nueva conducta general. La irrupción de su figura se inscribe en una de las tantas disputas entre liberales y conservadores al momento de configurar el Estado nación, donde se potencia un discurso moralizador con un énfasis en el desarrollo industrial.

Con el objetivo de especificar de forma práctica la influencia del proyecto educativo de Pedro Chapuis, es menester detenerse a identificar las características del Colegio de Santiago en relación con el Liceo de Chile, los establecimientos que representan a los dos principales bandos en disputa.

Ruth Aedo-Richmond realiza un estudio sobre la educación privada en Chile, en el que se detiene a analizar estas dos instituciones. Especifica que el Liceo de Chile fue creado por José Joaquín de Mora, con el fuerte apoyo de los liberales, especialmente, por el presidente Pinto, quien ayudó a financiar alrededor de cuarenta becas para estudiantes. Hubo acusaciones de que, para el financiamiento de este Liceo, se utilizaron fondos del Estado, cuestión que afectó directamente al Instituto Nacional (Aedo-Richmond, 2000, pp. 36-37). Esta práctica encontró rápidamente detractores en el bando conservador. Ejemplo de ello lo encontramos en un periódico apoyado por Diego Portales, quien en ese momento tenía relación cordial con Pedro Chapuis.

El programa curricular del Liceo de Chile era el siguiente. Dividido en dos áreas, científica y humanista, tenía una duración de cinco años. Las asignaturas que se impartían eran Latín, Francés, Geografía, Historia, Literatura Española y Francesa, Leyes y Retórica. El programa 
científico fue dirigido por Antonio de Gorbea, en él se incluía Matemática pura, Física, Química, Astronomía y Comercio. Los textos de estudio de Gramática castellana y francesa, Literatura, Geografía y Leyes fueron escritos por el mismo Mora (Aedo-Richmond, 2000, pp. 36-37).

El Colegio de Santiago, apoyado por conservadores, y dirigido por el sacerdote Juan Francisco Meneses, quien, según Ruth Aedo-Richmond, "había renunciado como rector del Instituto Nacional, porque el Gobierno se negó a dar los fondos necesarios para aumentar el profesorado del plantel" (Aedo-Richmond, 2000, pp. 36-37). Dentro de las materias que impartía, se encuentra Filosofía, Matemáticas, Geografía, Historia, Dibujo, Música, Retórica y Leyes (AedoRichmond, 200, pp. 36-37). Cabe recordar que la planta docente estaba guiada fundamentalmente por los profesores franceses invitados por Pedro Chapuis y que, posterior a su llegada, debido a los problemas descritos en el apartado anterior, se unen a Meneses y Portales para dar inicio a este Colegio.

Como fuente contemporánea a la época de estudio, tenemos el discurso inaugural del Colegio de Santiago, en el que Meneses habla de la importancia de la educación científica y moral (Velasco \& Orrego, citando a la Gaceta de Chile, p. 333). Esta moralidad, si la analizamos desde Émile Durkheim, podemos entenderla como la búsqueda del disciplinamiento por la vía de la imposición de formas de pensar, a través del sistema educativo. De tal suerte que, "cuando una forma de actuar se convierta en habitual en un grupo, todo lo que se aleje de ella suscita un movimiento de reprobación”. (Durkheim, 2002 [1922], p. 55).

Sobre la influencia de la religión como un aspecto para la modificación de las costumbres y la moral, exponemos un fragmento de una carta publicada el 18 de mayo de 1827 en El Verdadero Liberal, donde se explica la relación que existe entre religión e ilustración:

Debe pues la religión, para que obre sus saludables efectos ser enseñada, pero no como se enseña regularmente, haciendo decir a los niños unas oraciones, y preguntar y responder un pequeño catecismo, de lo que quedan en ayunas, pues todo esto lo repiten como el papagayo (...). Por esto es que yo quisiera lo primero: que todos los párrocos en los días de fiesta por la tarde explicasen la doctrina cristiana a sus feligreses, y que todos fuesen obligados, por lo menos los padres de familia, a asistir, a las parroquias. (...) Que la explicación sea en un estilo sencillo, claro y perceptible: que en ella se viertan y se explayen las máximas santas. (Chapuis, El Verdadero Liberal, 1827, №57, p. 2).

Si bien el establecimiento era pagado, en un principio se dieron diez becas "para que fuesen ocupadas por cinco jóvenes que podía elegir y designar el Presidente de la República, cuatro al arbitrio de la Municipalidad de Santiago y uno al del Intendente de la misma capital. Lo 
interesante de esta garantía estatal, es que dentro de los requisitos, no basta el aspecto económico, sino que en la institución de las becas quedó también establecido que estos beneficiados 'deberían ser los hijos de aquellas familias beneméritas a quienes acaso sus servicios a la patria han causado en su fortuna una decadencia tal que no les presta abitrios para costear la educación de sus hijos'” (Silva, 1965, p. 41). Por lo tanto, lo que se privilegia es el sacrificio por participar de alguna u otra forma en este proceso de construcción de Estado, limitándose de esta forma el porcentaje de la población que puede acceder a este tipo de beneficio.

Posterior al triunfo conservador en Lircay, Andrés Bello pasó a ser director del Colegio de Santiago. Introdujo dos cursos nuevos: Gramática Castellana y Teoría de la Legislación. Finalmente, este establecimiento cerró sus puertas en 1834 por falta de recursos financieros (Aedo-Richmond, 2000, pp. 36-37).

Para hacerse una idea estadística de la cobertura educativa a fines de la década de 1820, entre el Liceo de Chile, el Instituto Nacional y el Colegio de Santiago "sumaban un total de 982 alumnos secundarios y además tenían un total de 318 alumnos en sus escuelas elementales" (Aedo-Richmond, 2000, pp. 36-37). Es decir, apenas superaban el millar de estudiantes.

Tras serle arrebatada la posibilidad de dirigir el Colegio de Santiago, Pedro Chapuis reaparece con un nuevo vuelco discursivo. Comenzó a argumentar contra los estanqueros, debido principalmente al monopolio comercial que ejercían, y la ambición personal que los separaba de la ciudadanía. Denuncia Chapuis que "los estanqueros han hecho a la nación todo el mal que podían hacerle, y no será el menor de ellos el prurito de volverse a imponer su yugo. (...) El estanco tiene dinero, y el egoísmo es el vínculo de su unión" (Chapuis, El Verdadero Liberal, 1829, $N^{\circ} 69$, p. 1). A este grupo, los denomina como una secta política (Chapuis, El Verdadero Liberal, 1829, $\mathrm{N}^{\circ} 69$, p. 4). De esta forma, surge el apoyo al bando liberal, que le significaría a Chapuis su expulsión tras la Batalla de Lircay.

En consecuencia, "muchas plumas se convirtieron en puñales" (Velasco \& Orrego, 1872-73, p. 335). Los periódicos y establecimientos educativos fueron campos de batalla intelectual para imponer patrones conductuales en la población. A pesar de que estos dos colegios privados hayan cerrado a la brevedad, fueron fiel reflejo de un período motivado por los intereses personales, con un marcado discurso ilustrado, universalista y dirigido, en primera instancia, a un grupo acotado de la sociedad.

\section{Proyecciones del sistema educativo durante la primera mitad del siglo XIX}

El proyecto de Pedro Chapuis se ve truncado y, con el transcurso de los años, el Liceo de Chile y el Colegio de Santiago cierran. A pesar de ello, existen ciertas ideas de las cuales el francés es parte, principalmente el discurso civilizatorio e ilustrado, que continúa en pie y que signa todo el siglo XIX. Podemos interpretar que tanto liberales como conservadores, son herederos del liberalismo, básicamente en el aspecto teórico. Pero en la forma de proponer el sistema de gobierno que se va a establecer en el Chile independiente, se generan sus principales diferencias y vicisitudes. El paradigma ilustrado marca a otros referentes intelectuales de 
mediados del siglo XIX, período que la historiografía nacional denomina como el comienzo del auge de la educación formal impartida desde el Estado. A continuación, se presentan algunas de estas proyecciones, que nacen en la primera mitad del siglo XIX, pero que ven sus mayores frutos prácticos en las décadas posteriores.

En primer lugar, se encuentra la Escuela Normal de Preceptores, que es fundada en el año 1842. Con esta institución, por primera vez el Estado nación chileno, a través de su aparato burocrático, se ocupa de la instrucción, formación de sus habitantes (Ley Escuela Normal de Preceptores, 1842), para "culturizar a las masas" (González, 2011, p. 293). Recordemos que el gran hito de Pedro Chapuis fue invitar al grupo de intelectuales franceses a Santiago de Chile para fomentar la educación, cuando en este territorio no existían personas preparadas profesionalmente para la docencia.

Hacia la década de 1840, se busca aumentar la cobertura educativa y, a partir de 1842, el presupuesto ministerial comenzó a acrecentar de forma constante. Es así como en tres años, de 1842 a 1845, el presupuesto para proyectos educacionales se triplica (González, 2011, p. 247). El país empieza a preparar a sus propios intelectuales, no tan sólo para la construcción de conocimiento -que se difunde principalmente en periódicos- sino también por la importancia de tener personas idóneas que puedan enseñar y transmitir este aprendizaje a los futuros preceptores.

En la década de 1840, nace el plan de educación secundaria, que comienza formalmente en 1843 "con la creación de un Plan Humanista y con un marcado sentido nacional y homogéneo que las autoridades le imprimieron desde un principio" (González, 2011, p. 248). Algunos historiadores, como la Premio Nacional de Historia, Sol Serrano, sostienen que "la alfabetización era un proceso que daba sus primeros pasos en la sociedad chilena cuando el primer censo la midió a mediados del siglo XIX" (Serrano, Ponce de León, Rengifo, 2012, p. 137), en un período que coincide con el aumento presupuestario para la educación y la formación de preceptores.

Para culminar, "el Censo General de 1854 fue un hito político y educacional que da cuenta de las dificultades del proceso de construcción territorial del Estado decimonónico y de las grandes limitaciones que enfrentó por alcanzar a sus habitantes" (Serrano, Ponce de León, Rengifo, 2012, p. 94). Pero a pesar de estas dificultades, "por primera vez, el censo de 1854 preguntó por cuántos sabían leer y escribir." (San Martín, 2010, pp. 120-121).

A modo de síntesis de estas proyecciones educativas, coincidimos con los historiadores que plantean que el Estado docente toma fuerza a mediados del siglo XIX. Sin embargo, esto no quiere decir que previo a dicho período no existieran proyectos educativos. Pero para la consecución de las políticas educacionales establecidas durante la segunda mitad del siglo XIX, fue fundamental pasar por un proceso transitorio de propuestas sobre la instrucción de la población. Allí, Pedro Chapuis formó parte de este largo proceso. El viaje de Chapuis con el grupo de franceses a radicarse en Chile, para fomentar la instrucción, investigar y construir conocimiento, puede ser interpretado como antecedente de la Escuela Normal de Preceptores. 


\section{Consideraciones finales}

Como síntesis, planteamos que Pedro Chapuis fue un personaje conflictivo en cada territorio en el que residió. Conflictivo, debido a sus ideales liberales, ya sea desde una óptica centralista o federalista, en el discurso de Chapuis está muy presente la idea de leyes naturales, del bien común, de la llustración como proceso formador y del progreso, a partir de planteamientos que proponen unificar el poder, principalmente por la ignorancia de la población y la escasa instrucción que les impedía llevar a la práctica estos ideales ilustrados. Su visión racionalista no genera simpatías en los gobiernos de Francia, Portugal, España, Brasil, Chile ni Perú. Esto se debe al escepticismo por su capacidad crítica, y a la búsqueda de comprobación. Hay también en Chapuis un cierto optimismo, ya que no duda de la razón ni de la voluntad en el progreso general.

Respecto de su proyecto educativo, aunque es un fracaso como empresa personal, puesto que no alcanza a llevar a la práctica sus ideas ilustradas, sí triunfa la construcción del sistema educativo formal. Con todas las críticas que se les pueda hacer, los forjadores del Estado nación chileno, con sus aparatos burocráticos, tienen sus bases en la primera mitad del siglo XIX. A mediados de éste, comienza lo que la historiografía llama el Estado docente. A esto hay que sumar que, a nivel latinoamericano, la influencia francesa es bastante notoria desde el punto de vista educativo. En consecuencia, más que militares, son comerciantes, intelectuales y redactores de periódicos, quienes en sus postulados van expresando una ideología que trasciende a través del sistema educativo formal, con el moldeamiento de las costumbres, y la transformación de las mentalidades y la moral, a fin de fomentar la libertad individual, la industria, la igualdad ante la ley y la extracción y explotación de recursos naturales. Esta mentalidad todavía se ve en nuestra actualidad, donde continúa un proceso de aculturación, que persigue eliminar ciertas tradiciones indígenas y campesinas del Chile decimonónico y del siglo XX, a partir del modelamiento de un ciudadano útil y leal para el Estado.

Sobre el Colegio de Santiago, es ejemplo de un establecimiento de corte privado, financiado con fondos estatales, como fiel reflejo de la polarización política. Dentro de las materias a impartir estaba la filosofía, las matemáticas, la geografía, la historia, el dibujo, la música, la retórica y las leyes, pasando desde el campo científico al humanista. De esta forma, en la primera mitad del siglo XIX se generan proyecciones para el establecimiento, en 1842, de la Escuela de Preceptores, con ayuda del aumento al presupuesto nacional. Un año después se creó el Plan Humanista, para impulsar la homogeneidad social. Y, en 1854, el censo preguntó por vez primera sobre las personas que saben leer y escribir. Con esto, los aparatos burocráticos del Estado tienen una eficaz herramienta para generar un diagnóstico y continuar proyectando el establecimiento de nuevas normas y planes de acción desde el sistema educativo formal. 


\section{Referencias}

\section{Fuentes primarias}

Chapuis, Pedro. El Verdadero Liberal, 1827-1829.

Discurso leído por don Francisco Vidal Gormaz en el acto de su incorporación a la Facultad de filosofía i humanidades, en sesión de 15 de octubre de 1874.

Ley del 18 de enero de 1842 que crea la primera Escuela Normal de Preceptores.

Núñez, J. A. (2010). Organización de las escuelas normales. Santiago de Chile: Cámara Chilena de la construcción.

Sarmiento. D. (1987). Educación común. Buenos Aires: Ediciones Solar.

Sarmiento, D. F. (2009). De la Educación Popular. Santiago de Chile: Cámara Chilena de la construcción.

\section{Fuentes secundarias}

Aedo-Richmond, R. (2000). La Educación Privada en Chile: Un estudio histórico-analítico desde el período colonial hasta 1990, Santiago de Chile: Ril Editores.

Aljovín, C. y Araya, E. (2005). Prácticas políticas y formación de ciudadanía. En Cavieres y Aljovín (Comp.), Chile - Perú, Perú - Chile: 1820 - 1920. Desarrollos políticos, económicos y culturales. Valparaíso: Ediciones Universitarias de Valparaíso.

Altieri, Á. (1970). La doctrina político-social de Rousseau en el marco del iluminismo. México: Editorial José M. Cajica.

Berbel Reginal, M. (2009). Autonomía y soberanía nacional en vísperas de las independencias iberoamericanas. En Stuven y Pamplona, Estado y nación en Chile y Brasil en el siglo $X I X$. Santiago de Chile: Ediciones Universidad Católica de Chile.

Biografía de Claudio Gay. Revista Chilena, Santiago de Chile, 1875-76, vol. II, pp. 116, 209,70 i 564 vol. II, p. 5; en los Anales de la Universidad, 1875, vol. 49 i 1876, vol. 50, pp. 137227.

Durkheim, E. (2002) [1922]. La educación moral. Madrid: Morata.

Freire, P. (1970). Pedagogía del oprimido. Santiago de Chile: Editorial ICIRA.

González, M. (2011). De empresarios a empleados. Clase media y Estado Docente en Chile, 1810-1920. Santiago de Chile: LOM Ediciones.

Oakeshott, M. (1947). El Racionalismo en la Política, Publicado originalmente en Cambridge Journal, Vol. 1 e incluido posteriormente en Michael Oakeshott, Rationalism in Politics and Other Essays, prologado por Timothy Fuller, edición ampliada (Liberty Press, Indianapolis, 1990 [Primera edición, Londres y Nueva York: Methuen \& Co. Ltd., 1962]).

Puigmal, P. (2012). Napoleónicos, europeos y liberales, en la Independencia americana: dos casos de estudio: Chile y México. Tiempo Histórico, 5, 15-35.

Puigmal, P. (2013). Brasil bajo influencia napoleónica y francesa. Los mensajeros de la Independencia: Militares, libreros y periodistas. Revista Historia, 46 (I), 113-151.

Puigmal, P. y Núñez, R. (2010). La imagen de Chile y de los chilenos a través de los escritos de la oficialidad napoleónica durante la Independencia: 1817-1830. Alpha, 31.

San Martín, E. (2010). Sarmiento, modernidad e instrucción pública: relaciones construidas desde la estadística. Revista Pensamiento Educativo, V, 46 y 47: Dos siglos de educación: Historia de ideas, instituciones y prácticas".

Serrano, S.; Ponce de León, M. y Rengifo, F. (2012). Historia de la Educación en Chile (18102010), Tomo I, Aprender a leer y escribir. Santiago de Chile: Taurus.

Silva Castro, R. (1965). Don Andrés Bello. 1781-1865. Santiago de Chile: Editorial Andrés Bello.

Velasco, F. y Orrego, A. (Dir.). (1872-1873). Revista de Santiago, I/ (16). 
Villagra, Yerko. (2017). El proceso de formación de la República en Chile, mirado desde la prensa nacional del periodo 1823-1830. (Tesis de Magíster inédita). Magíster en Ciencias Humanas, mención Historia. Universidad de Los Lagos. 